\title{
EXPERIMENTAL RESEARCH OF THERMOPHYSICAL PROCESSES IN A CLOSED TWO-PHASE THERMOSYPHON
}

\author{
D.V. Feoktistov ${ }^{1, *}$, E.A. Vympin ${ }^{1}$, and $A$.E. Nurpeiis ${ }^{1}$ \\ ${ }^{1}$ National Research Tomsk Polytechnic University, 634050 Tomsk, Russia
}

\begin{abstract}
The temperature distribution in a thermosyphon was studied experimentally. To conduct the research, a closed two-phase thermosyphon was developed, which differs from the known by simple construction. The method of studying the rapid processes of conduction, convection and phase transitions was also developed. It will allow to highlight the operational modes of the thermosyphon, considering the load, cooling conditions of the condensation section, value of the heat supply. According to obtained results the instabilities of the temperature fields over the crosssection of the two-phase closed thermosyphon were observed by means of using the modern measuring equipment. It has been suggested that the instabilities can be caused by different modes of thermosyphon operation.
\end{abstract}

\section{Introduction}

Two-phase thermosyphons are simple in design, effective as thermal engineering devices that can remove the high local heat releases. Unfortunately, such cooling systems are not widely used in industry due to the lack of scientific basis for their design. However, their application has shown high effectiveness. For example, to regulate the thermal regime of heat engineering constructions in Yamal, to compensate the linear expansions of TransSiberian railways and backup abutment of oil pipelines in Alaska.

The known experimental studies of such heat removal systems are focused on the finding the optimal values of the amount, chemical composition and pressure of the coolant, which would ensure the most effective operation of the particular design of the thermosyphon [1-2].

At the same time the fundamental bases of jointly proceeding processes of conduction [3], convection [4-6] and phase transition [7-16] are not studied at level to provide the design of energy efficient heat removal equipment.

This paper aims to study experimentally the temperature distribution in a two-phase closed thermosyphon. The second and major task undertaken was to develop the methods of conducting experiments to study jointly proceeding processes of conduction, convection and phase transition.

\footnotetext{
Corresponding author: fdv@,tpu.ru
} 


\section{Materials and methods}

Experimental studies were carried out on the experimental setup. Its schematic diagram is shown in figure 1.

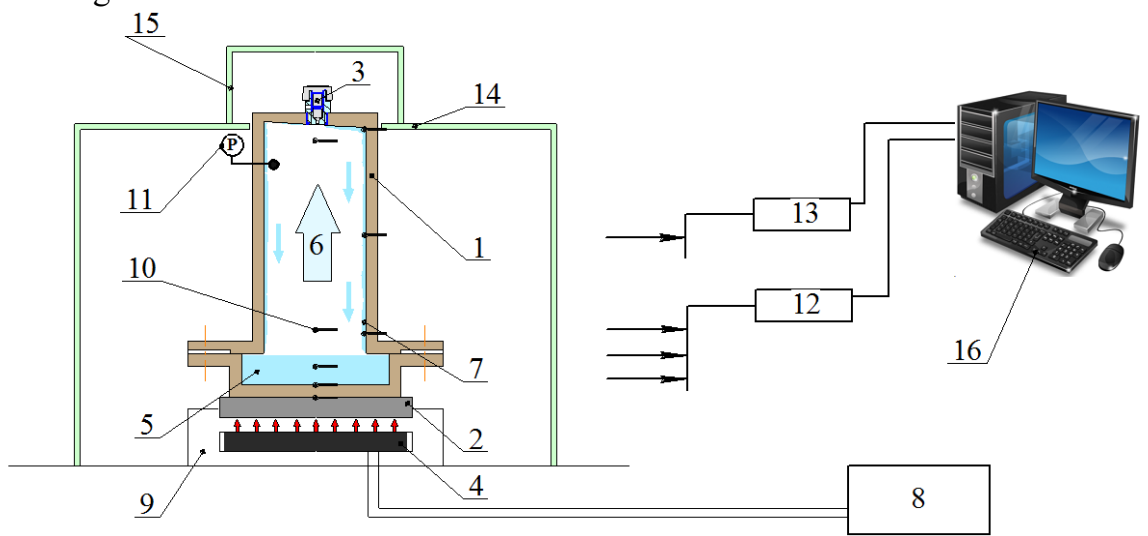

Fig. 1. Schematic diagram of the experimental setup: 1 -thermosyphon; 2 - metal substrate; 3 - valve; 4 - heating spiral; 5 - working liquid; 6 - liquid vapour; 7 - condensate; 8 - power supply, 9 - working table; 10 - thermocouples; 11 - pressure sensor; 12 - analog-to-digital converter NI 9214; 13 - analog-to-digital converter NI USB-6000; 14 - glass box; 15 - cover for an upper opening; 16 - personal computer.

The layout of the thermocouples and pressure gauge is presented in figure 2 .

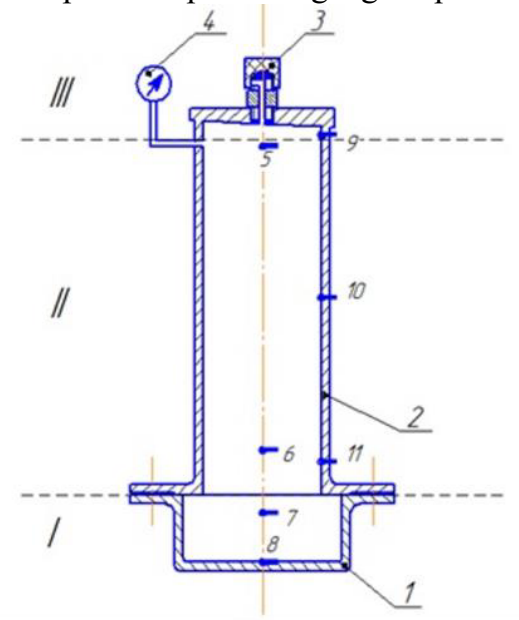

Fig. 2. Layout of the thermocouples and pressure gauge: I - evaporative part; II - vapour channel; III - condensation part; 1 - bottom cover; 2 - top cover; 3 - valve for pressure control; 4 - pressure sensor; 5-11-thermocouples.

Thermosyphon is made of copper. It consists of two sections: the lower 1 and upper 2 covers, fastened by eight screws with a diameter of $6 \mathrm{~mm}$. The thickness of the side walls is $1.5 \mathrm{~mm}$; the bottom wall is $2 \mathrm{~mm}$. The upper wall is inclined at an angle of $3^{\circ}$ to the horizon. It provides the movement of the condensate along the wall. A threaded opening is made for the valve 3 in the upper wall. The valve is designed to control the pressure in the thermosyphon.

The construction of thermosyphon can be divided into three working sections: evaporative I, vapour II and condensation III (fig. 2). The bottom cover of the 
thermosyphon with an inner diameter of $54 \mathrm{~mm}$, a volume of $50 \mathrm{ml}$ operates as an evaporative part. Two thermocouples recording the temperature of the liquid and the bottom of the thermosyphon are installed in this section.

The vapour channel is made of copper pipe with an internal diameter of $39.2 \mathrm{~mm}$. Here, the temperatures of vapours are measured by thermocouples mounted in the lower, upper and central parts. Their position is shown in figure 2 .

The upper wall of the thermosyphon operates as a condensation part III. The temperature of the condensate, moving on the side wall, is measured by the thermocouples $9,10,11$. Vapour pressure is registered by sensor 4 .

According to the preliminary series of experiments it was found that the operation of the thermosyphon significantly affected by the external factors, such as the presence of staff, changes in the flow of air masses in the laboratory because of the doors, windows opening, etc.). To reduce the impact of these factors on the research, thermosyphon was covered by glass box.

Box was made of plexiglass of $3 \mathrm{~mm}$ thick (fig. 3). The construction has the openings for mounting of the thermocouples 3 and cable from the heater 2 , and the opening on the upper wall.

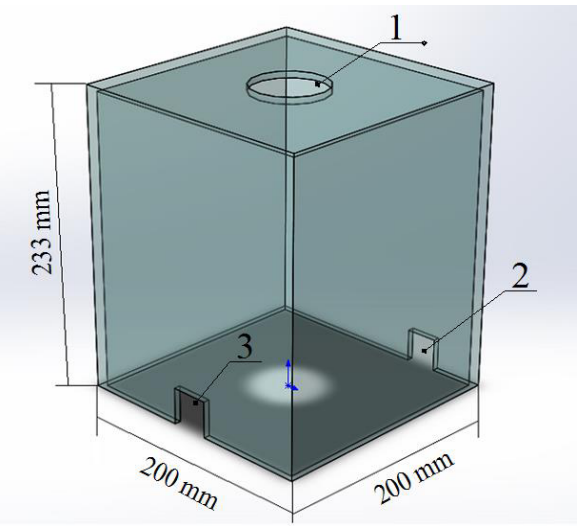

Fig. 3. Plexiglass box: 1 - opening for access to the condensation section of the thermosyphon, 2,3 -openings for mounting thermocouples and heater cable.

\section{Results and discussion}

According to results of the preliminary experiments the possible ranges of the significant factors were determined (Table 1).

The maximum volume of filling $(50 \mathrm{ml})$ of the thermosyphon was chosen based on the size of the evaporative section. Operating conditions of the thermosyphon, when it is filled less than on $20 \%$ (from the evaporative section), are considered as emergency due to the formation of dry spots on the walls. The variation of the heating power was made in accordance with the conditions of the unit. Distilled water and $3 \mathrm{M}^{\mathrm{TM}}$ Novec $^{\mathrm{TM}} 7100$ engineered fluid were chosen as the working liquids because of their physical properties. Water is cheap and readily available coolant. $3 \mathrm{M}^{\mathrm{TM}}$ Novec ${ }^{\mathrm{TM}} 7100$ is low-boiling liquid with a boiling point of $61^{\circ} \mathrm{C}$ and a density of $1.52 \mathrm{~g} / \mathrm{ml}$, has a low surface tension, strength to thermal and chemical impact, non-flammability and low toxicity. 
Table 1. The main significant factors.

\begin{tabular}{|c|c|}
\hline Factors & Values \\
\hline $\begin{array}{c}\text { Volume of filling of thermosyphon, } \mathrm{ml} \text { (\% from } \\
\text { evaporative section) }\end{array}$ & $10-50(20-100)$ \\
\hline Power of heating, $\mathrm{W}$ & $3-40$ \\
\hline Working liquid & $\begin{array}{c}\text { distilled water, } \\
\text { WM } 7100 \text { engineered fluid }\end{array}$ \\
\hline
\end{tabular}

The temperature was measured using calibrated thermocouples $\mathrm{K}$ type (OMEGA 5TCTT-K-40-36) with a thermojunction of 80 microns. The responses were tested with standard resistance thermometers ETS-100 with the error in the test temperature ranges of $0.05{ }^{\circ} \mathrm{C}$. The measured values of the temperatures were saved on the personal computer with the help of analog converter National Instruments 9214 (NI 9214) and developed software LABVIEW Signal Express 2012. The usage of modern equipment allowed to record fast processes of conduction, convection and phase transitions. The estimation of measurement errors was carried out as described in [15]. According to results of calculation the error does not exceed $2 \%$.

Figure 4 shows a typical thermogram obtained during the preliminary experiments. Distilled water with volume of $30 \mathrm{ml}$ was used in these experiments; the heating value was 28 in watts. The experiment was conducted without measures for intensifying heat transfer (forced cooling of condensation section of thermosyphon by moistening or air blowing). Also the recorded values from the pressure sensor located in the condensation section are presented in fig. 4.

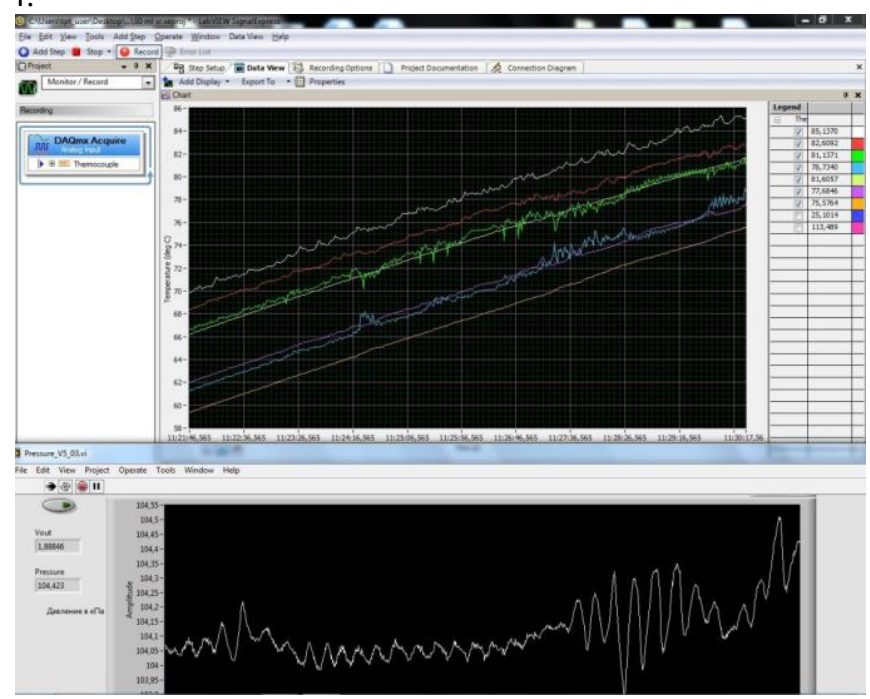

Fig. 4. Screenshots of software for recording the temperature and pressure.

According to analysis of the thermograms and corresponding pressure values it was found that there are significant instabilities of the temperature fields over the cross-section of the two-phase closed thermosyphon. Registered temperature fluctuations in the vapour section correspond to the temperature "jumps" of liquid at the bottom of the thermosyphon and pressure in the condensation section of the unit. Probably, these instabilities are caused by different operational modes of the thermosyphon, which depend on the boiling regimes. It is also found that the specific heat flux during operation of the thermosyphon is changed regardless the amount of heat supplied to the lower part of the thermosyphon and volume of filling. 
Before reaching the boiling point of the liquid in the thermosyphon the instabilities of the temperature fields, as well as the change in specific heat flux are strongly marked. Presumably, this fact can be explained by the change in the boiling mode occurring in thermosyphon during its operation.

\section{Conclusions}

In conclusion it should be noted, that one of the main achievements of this work is to develop the two-phase closed thermosyphon, which differs from the known by simple construction. The instabilities of the temperature fields over the cross-section of the twophase closed thermosyphon were observed by means of using the modern measuring equipment for registration of the temperature and pressure. To the best of our knowledge, these instabilities can be caused by different modes of thermosyphon operation.

The developed method of studying the rapid processes of conduction, convection and phase transitions will allow to highlight the operational modes of the thermosyphon, considering the load, cooling conditions of the condensation section, value of the heat supply. Also in this work the backgrounds were developed for an explanation of the physical mechanism of processes in the two-phase thermosyphon, the determination of transition conditions from one boiling mode to another.

\section{Acknowledgments}

The reported study was supported by the grant of President of Russian Federation for the government support of young Russian scientists (MK-6810.2016.8).

\section{References}

1. Marchuk I., Lyulin Y., Kabov O., Interfacial Phenomena and Heat Transfer 1 (2), 153 (2013)

2. D. Attinger, Z. Zhao, D. Poulikakos, Heat Mass Transfer 122, 544 (2000)

3. A.E. Nurpeiis, EPJ Web Conf. 76, 01016 (2014)

4. S.Ya. Misyura, Int. J. Heat Mass Transfer 71, 197 (2014)

5. V. E. Nakoryakov, S. Y. Misyura, S. L. Elistratov, J. Eng. Thermophys. 22, 1 (2013)

6. O.A. Kabov, D.V. Zaitsev, Multiphase Sci. Technol. 21, 249 (2009)

7. D.O. Glushkov, G.V. Kuznetsov, P.A. Strizhak, Therm. Sci. 19, 1541 (2015)

8. G.V. Kuznetsov, A.V. Zakharevich, N.S. Bel'kov, Chem. Pet. Eng. 50, 424 (2014)

9. D.O. Glushkov, J.-C. Legros, P.A. Strizhak, A.V. Zakharevich, Fuel 175, 105 (2016)

10. D.V. Zaitsev, O.A. Kabov, Microgravity Sci. Technol. 19, 174 (2007)

11. Y.V. Lyulin, D.V. Feoktistov, I.A. Afanas'ev, E.S. Chachilo, O.A. Kabov, G.V. Kuznetsov, Tech. Phys. Lett. 41, 665 (2015)

12. V.I. Maksimov, T.A. Nagornova, V.S. Chernyshev Conditions and characteristics of water crystallization on the working surface of evaporator heat pumps in reservoirs with low temperatures, MATEC Web Conf. 23 (2015)

13. K. Ponomarev, E. Orlova, D. Feoktistov, EPJ Web Conf. 110 (2016)

14. G.V. Kuznetsov, D.V. Feoktistov, E.G. Orlova, Thermophysics and Aeromechanics 23, 17 (2016)

15. N.A. Yaryshev, Theoretical Fundamentals of Non-Stationary Temperature Measurements (Energoatomizdat, Leningrad, 1990)

16. A.S. Krasnoshlykov, V.I. Maksimov, EPJ Web Conf. 82 (2015) 